\title{
PHOTOSTABILITY OF ACETYLATED WOOD COATED WITH NANO ZINC OXIDE
}

\author{
Giridhar B Nagarajappa ${ }^{1}$,Sreeja Nair ${ }^{1}$, Kavyashree Srinivas ${ }^{1}$, Anantha N Subba Rao ${ }^{1}$, \\ Krishna K. Pandey ${ }^{1,4}$
}

\begin{abstract}
Chemical modification with acetic anhydride is an effective method to stabilise wood against dimensional movement and improve decay resistance of wood. It has also been reported to retard UV light induced color darkening on wood surface. Coatings of wood surfaces with certain nano metal oxides have also shown promise as UV screening agent. In this work, we have evaluated synergistic effect of acetylation of wood and application of nano material on wood surfaces to enhance their UV stability. Photo-stability of acetylated Wrightia tinctoria wood coated with zinc oxide $(\mathrm{ZnO})$ nanodispersion was evaluated by irradiating these wood specimens to UV radiation in an accelerated weathering tester. Acetylation of wood with acetic anhydride exhibited photo-bleaching and inhibited light-induced color darkening observed in unmodified wood. Coating of unmodified and modified wood surfaces with $\mathrm{ZnO}$ nanodispersion reduced photo-discolouration and degradation of wood polymers. The photo-bleaching observed in chemically modified wood upon light irradiation was further enhanced by application of nano coating on wood surfaces.
\end{abstract}

Keywords: Chemical modification, nano material, photodegradation, wood surface, Wrightia tinctoria, zinc oxide.

\section{INTRODUCTION}

Wood and wood products exposed outdoors are prone to abiotic and biotic degradation and require protective measures under outdoor applications. All the polymeric components of wood (cellulose, hemicelluloses and lignin) possess free hydroxyl groups, which make wood hydrophilic and results in its dimensional instability due to moisture absorption or desorption. Affinity to moisture also promotes microbial attack. Strong absorption of UV light by wood polymers, particularly lignin, makes wood surfaces susceptible to degradation due to solar radiation. Chromophores in lignin strongly absorb UV radiations and are prone to photochemical degradation. Degradation occurs through a series of free radical initiated chemical reactions resulting in accumulation of carbonyl moieties leading to photo-yellowing of the exposed wood surfaces (Feist and Hon 1984, Hon and Chang 1984, Tolvaj and Faix 1995, Hon 2001, Muller et al. 2003, Pandey 2005). The properties of wood can be upgraded by esterification of hydrophilic hydroxyl groups to make it hydrophobic. The chemical modification enhances biological resistance, reduces moisture adsorption and imparts dimensional stability of wood (Rowell 2005, Rowell 2006, Rowell 2013, Takahashi 1996, Plakette et al. 1996, Matsuda 1996, Giridhar et al. 2017). One of the most efficient modification processes is esterification with acetic anhydride (Rowell 2005, Rowell 2013, Rowell 2005, Chang and Chang 2002). It also provides UV resistance and inhibits light induced darkening (yellowing) of wood surfaces and therefore modified wood retains its natural appearance for longer duration (Rowell 2017, Vollmer and Evans 2013, Pandey and Srinivas 2015, Evans et al. 2000, Williams 2005, Nagarajappa and Pandey 2016). Chemical modification of wood with acetic anhydride is also effective in decreasing light induced discoloration (Evans et al. 2000, Chang and Chang 2001, Pandey and Pittman 2002, Ohkoshi 2002). 
Certain inorganic metal oxides (e.g., zinc oxide, titanium dioxide etc.) act as UV stabilizer by absorption or scattering of light. Reduction of the size to nanometer scale further enhances light absorption by these materials due to increased surface area. Coating with these inorganic nanoparticles has been found to induce UV resistance in wood to considerable extent (Clausen et al. 2010, Lowry et al. 2008, Cristea et al. 2010, Sahin and Mantanis 2011, Forsthuber et al. 2013, Habibzade et al. 2014, Afrouzi et al. 2013, Nair et al. 2018).

In this work, we had investigated influence of $\mathrm{ZnO}$ nanoparticle coating on UV stabilization of chemically modified wood. Wood specimens of Wrightia tinctoria were chemically modified with acetic anhydride. Unmodified and acetylated wood surfaces were coated with $\mathrm{ZnO}$ nanodispersions in propylene glycol using a sprayer and were irradiated with UV light in a QUV accelerated weathering tester equipped with UVA-340 $\mathrm{nm}$ light source. Extent of degradation was analyzed by evaluating color changes (using spectrocolorimeter) and chemical changes (monitored by using FTIR spectroscopy) on wood surfaces. In an earlier work, we had examined the UV resistance of unmodified wood coated with dispersions of nano metal oxides ( $\mathrm{ZnO}$, cerium oxide and titanium oxide) and found that these nano materials were very effective in imparting UV resistance on wood surfaces (Nair et al. 2018). However, performance of nanomaterial coating on photo-stabilization of chemically modified wood has not been studied.

\section{MATERIALS AND METHODS}

\section{Materials}

Defect free specimens of Wrightia tinctoria wood of size $150 \mathrm{~mm}$ x $3,5 \mathrm{~mm}$ x $5 \mathrm{~mm}$ (length $\mathrm{x}$ width $\mathrm{x}$ thickness) were prepared. Acetic anhydride ( $99 \%$, AR grade) was purchased from Pallav Chemicals, Mumbai, India. Zinc oxide $(\mathrm{ZnO})$ nanopowder (particle size $<100 \mathrm{~nm}$ ) was purchased from Sigma Aldrich Chemicals Pvt. Ltd., Bengaluru, India. Propylene glycol (PG) and N-bromosuccinimide (NBS) (99,5\%) were purchased from Central Drug House, India.

\section{Nanodispersions of $\mathrm{ZnO}$ in PG}

Nanodispersion of $\mathrm{ZnO}$ in $\mathrm{PG}$ was prepared according to the procedure discussed elsewhere (Nair et al. 2018). A stable homogenous solution, without any agglomeration, was obtained by stirring nanoparticle-PG mixture for $10 \mathrm{~min}$ in a homogeniser (IKA T25 Digital Ultra-Turrax) followed by sonication in an ultrasonicator (Heischer Ultra sound Technology UP400S). UV-Visible absorption spectroscopy and Scanning Electron Microscopy (SEM) were used to characterise $\mathrm{ZnO}$ nanodispersion (Nair et al. 2018).

\section{Acetylation of wood}

Specimens of $W$. tinctoria (size $150 \mathrm{~mm}$ x 3,5 $\mathrm{mm}$ x $5 \mathrm{~mm}$ ) were acetylated with acetic anhydride using N-bromosuccinimide (NBS) as catalyst (concentration $2 \%$ weight /volume) as per the procedure described by Nagarajappa et al. 2015. Reaction was carried out in an oil bath (reaction conditions: temperature $-105{ }^{\circ} \mathrm{C}$, reaction time $-4 \mathrm{~h}$ ) in a glass vessel connected to a water condenser. The unreacted reagent (acetic anhydride) was removed by extracting modified wood specimens with acetone and toluene (1:1) in a Soxhlet extractor. Weight percent gain (WPG) was estimated from oven dried weight of unmodified $\left(\mathrm{W}_{\mathrm{o}}\right)$ and chemically modified $\left(\mathrm{W}_{\mathrm{m}}\right)$ wood using Equation 1.

$$
W P G=\left[\frac{W_{m}-W_{0}}{W_{0}}\right] \times 100
$$

\section{Evaluation of UV resistance}

Unmodified and acetylated wood specimens coated with $\mathrm{ZnO}$ nanodispersions (concentration 1,0\% and $2,0 \% \mathrm{weight} /$ volume, two coats). The amount of applied coating on the surface was $0,0008 \mathrm{~g} \cdot \mathrm{cm}^{-2}$ for $2 \%$ dispersion and $0,0004 \mathrm{~g} \cdot \mathrm{cm}^{-2}$ for $1 \%$ dispersion.

UV resistance was evaluated by exposing coated wood (four replicates for each case) in a QUV accelerat- 
ed weathering tester (Q-Lab, USA) (irradiation source: UVA-340 nm fluorescent light; irradiance: 0,68 W/m²; chamber temperature: $60^{\circ} \mathrm{C}$ ) with no relative humidity and no condensation cycles. The UV resistance was analyzed by evaluating color and chemical changes on the wood surfaces at regular interval (50h) of exposure.

A spectro-colorimeter (Hunter lab - Lab scan XE model) was used to estimate color changes using CIELab color co-ordinates. Changes in lightness $\left(\Delta \mathrm{L}^{*}\right)$, redness $\left(\Delta \mathrm{a}^{*}\right)$ and yellowness $\left(\Delta \mathrm{b}^{*}\right)$ were measured on each sample. Total color change $\Delta \mathrm{E}^{*}$ were evaluated using Equation 2,

$$
\Delta E^{*}=\left(\Delta L^{* 2}+\Delta a^{*^{2}}+\Delta b^{*^{2}}\right)^{1 / 2}
$$

FTIR - attenuated total reflectance technique was used to record spectra from wood surfaces using a FTIR spectrometer (Bruker model Tensor 27). Spectra were measured at a spectral resolution of $4 \mathrm{~cm}^{-1}$ with 64 scans/ measurement.

Contact angle of water droplet on unmodified and modified wood surface was measured using a contact angle analyzer by tangent fitting mode (Phoenix 300 Plus model and Surface Electro Optics make having LED light source with accuracy of $\pm 0,1^{\circ}$ ).

\section{RESULTS AND DISCUSSION}

\section{Acetylation of wood with acetic anhydride}

Acetylation of wood resulted in an average WPG of 20,5 $\pm 1,2$. Acetylated wood was characterised using FTIR spectroscopy (Figure 1). Significant reduction in the absorbance of band at $3347 \mathrm{~cm}^{-1}(\mathrm{O}-\mathrm{H}$ stretching) and increased absorbance of band at $1737 \mathrm{~cm}^{-1}(\mathrm{C}=\mathrm{O}$ stretching $)$ and $1214 \mathrm{~cm}^{-1}(\mathrm{C}-\mathrm{O}$ stretching $)$ indicates of esterification of wood. Reduction in available - $\mathrm{OH}$ groups due to acetylation makes wood hydrophobic and dimensionally stable. Hygroscopicity of the modified wood surface was ascertained by contact angle measurement. It was found that the contact angle on acetylated wood was $69^{\circ}$ in comparison to $44^{\circ}$ for unmodified wood (Figure 2). The hydrophobic nature of modified wood may influence the distribution and adhesion of nanocoating.

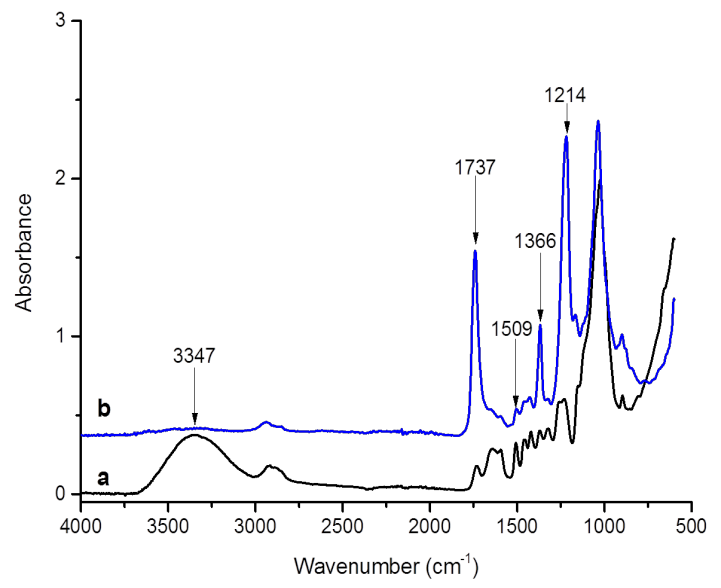

Figure 1: FTIR spectra of (a) unmodified and (b) acetylated Wrightia tinctoria wood. 


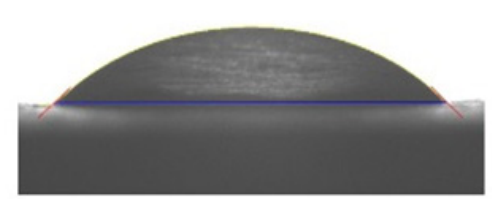

Unmodified Wood Contact angle $=44$

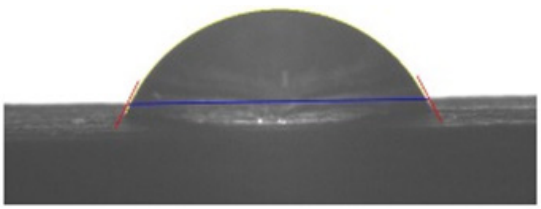

Modified Wood

Contact angle $=69$

Figure 2: Contact angle of unmodified and acetylated Wrightia tinctoria wood.

\section{Characterization of $\mathrm{ZnO}$ nano-dispersion}

A stable nanodispersion without any agglomeration was obtained by dispersing $\mathrm{ZnO}$ nano particles in PG. No additional surfactant or dispersing agent was used. UV absorption spectra show a broad absorption in UV visible region with $\lambda_{\max } \sim 374 \mathrm{~nm}$ (Figure 3 ). The nano dispersion of $\mathrm{ZnO}$ was very stable as ascertained using UV Visible spectroscopy (Nair et al. 2018). SEM analysis showed uniform distribution of nano particles in PG without any evidence of agglomeration (Figure 3).

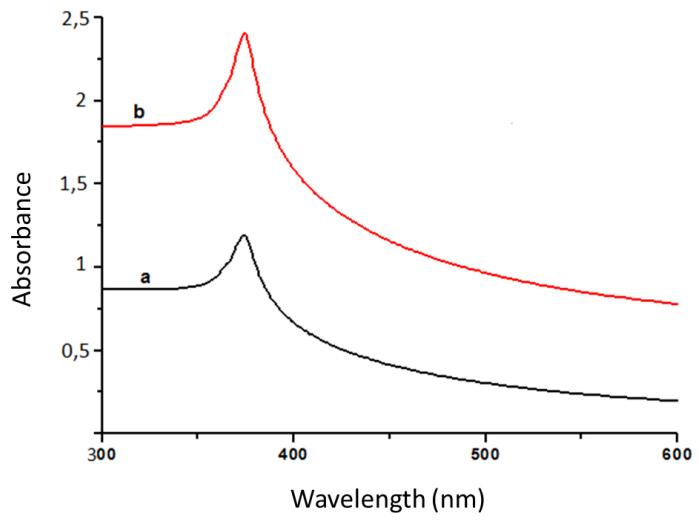

Figure 3: Absorption spectra of (a) $1 \%$ and (b) $2 \% \mathrm{ZnO}$ nanodispersions in PG.

\section{Photo-stability of coated wood}

\section{Color changes}

Untreated Wrightia tinctoria is a light colored wood with lightness index ( $\left.\mathrm{L}^{*}\right)$ of $79,7 \pm 0,6$. The color of unmodified wood surfaces turned yellow and dark on UV irradiation which is indicated by reduced lightness $\left(\mathrm{L}^{*}\right)$ with a corresponding rise in yellowness $\left(\mathrm{b}^{*}\right)$. The rate of change was high during initial period of exposure. Most of the color changes were observed within first $50 \mathrm{~h}$ of exposure. This trend in color changes is in agreement with several other studies on color changes in light irradiated wood (Tolvaj and Faix 1995, Muller et al. 2003, Pandey 2005, Pandey and Vuorinen 2008, Calienno et al. 2015, Gonzalez de Cademartori et al. 2015, Bonifazi et al. 2017, Capobianco et al. 2017, Timar et al. 2016, Zivkovic et al. 2016, Oberhofnerová et al. 2017).

UV irradiation of acetylated wood exhibited bleaching, as indicated by lighter color of the irradiated surface. Opposite to unmodified wood, $\mathrm{L}^{*}$ value increased indicating bleaching of acetylated wood on UV exposure. There was only a small change in $b^{*}$ upon exposure in acetylated wood. Change in lightness $\left(\Delta \mathrm{L}^{*}\right)$, yellowness $\left(\Delta \mathrm{b}^{*}\right)$ and total color changes $\left(\Delta \mathrm{E}^{*}\right)$ after $500 \mathrm{~h}$ of UV exposure for unmodified and acetylated 
wood are compared in Figure 4. As mentioned above, color of unmodified and PG coated specimens deepens/ darkened after irradiation with negative $\Delta \mathrm{L}^{*}$ values whereas, the color of acetylated specimens turned lighter as indicated by positive $\Delta \mathrm{L}^{*}$ values.

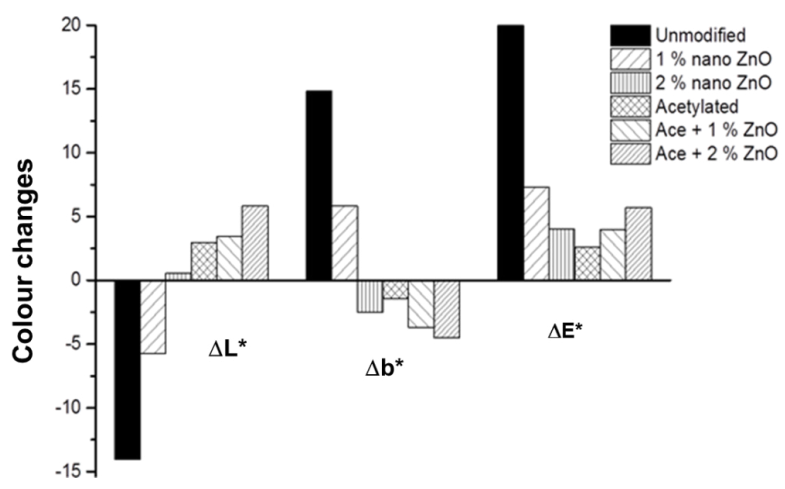

Figure 4: Change in lightness $\left(\Delta \mathrm{L}^{*}\right)$, change in yellowness $\left(\Delta \mathrm{b}^{*}\right)$ and change in total color $\left(\Delta \mathrm{E}^{*}\right)$ after $500 \mathrm{~h}$ of UV irradiation.

The effectiveness of nano-coating on UV stabilisation of unmodified and modified wood is clearly evident. Though the color darkening (photo-yellowing) was not observed in acetylated wood coated with nano $\mathrm{ZnO}$ dispersion, the overall color change $\left(\Delta \mathrm{E}^{*}\right)$ increased with nano coating application. The total color change in acetylated wood also increased with increase in nanoparticles concentration. This is attributed to the increased lightness of $\mathrm{ZnO}$ dispersion coated specimens.

Positive $\Delta \mathrm{L}^{*}$ values in acetylated wood showed brightening of wood rather than darkening observed in unmodified wood. Increase in other color co-ordinates viz., $\Delta \mathrm{b}^{*}$ and redness $\Delta \mathrm{a}^{*}$ for unmodified wood indicates the changes in yellowness and redness of the specimens due to UV exposure. These color changes of unmodified wood surfaces are generally attributed to the development of conjugated ketones, aldehydes, quinone-like structures involving free radicals mediated depolymerisation and oxidation of lignin (Hon and Chang 1984, Hon 2001, Pandey 2005). In case of acetylated wood, $\Delta \mathrm{b}^{*}$ values were found to be negative, showing opposite behaviour towards yellowness. These results indicate effectiveness of chemical modification in restricting light induced darkening /yellowing of wood. Similar observations of photo-bleaching of acetylated wood have been reported earlier (Mitsui 2010, Salla et al. 2012, Nagarajappa and Pandey 2016). Acetylation modifies wood structure and decreases photo-induced degradation by blocking the reactive sites (Hon 2001, Kalnins 1984, Temiz et al. 2006). These findings support findings of earlier studies (Evans et al. 2000, Ohkoshi 2002, Nagarajappa and Pandey 2016, Pandey and Chandrashekar 2006, Jebrane et al. 2009).

Color darkening of unmodified wood due to UV irradiations was suppressed by coating of wood surfaces with $\mathrm{ZnO}$ nanodispersions. The change in color parameters ( $\mathrm{L}^{*}, \mathrm{a}^{*}$ and $\mathrm{b}^{*}$ values) in unmodified wood coated with $\mathrm{ZnO}$ nanoparticles were significantly less than uncoated wood. The effectiveness of nano coating increased with increased concentration of nanoparticle. Coating of acetylated wood surfaces with $\mathrm{ZnO}$ nanoparticles also reduced light induced color changes. Coating of $\mathrm{ZnO}$ nanodispersion on acetylated wood increased its lightness upon exposure to UV light. Similarly, $\Delta \mathrm{b}^{*}$ values attained negative value upon longer exposure in acetylated wood. However, the extent of change in $b^{*}$ was very small in acetylated wood. Acetylated wood coated with higher concentration ( $2 \%$ nanodispersion) exhibited highest bleaching as indicated by increased $\Delta \mathrm{L}^{*}$ and reduced $\Delta \mathrm{b}^{*}$ compared to acetylated wood coated with lower concentrations of nanodispersion. Similarly, variation in redness $\left(\Delta \mathrm{a}^{*}\right)$ was least for acetylated specimens coated with $2 \%$ nano $\mathrm{ZnO}$ dispersion. Bleaching observed in acetylated wood due to light irradiation also increased with nano $\mathrm{ZnO}$ coating. It can be seen from Figure 5 that unmodified wood coated with nano dispersion also showed some bleaching effect at higher $\mathrm{ZnO}$ concentration. The photo-bleaching of acetylated wood further enhanced with application of nanoparticles coating. This explains enhanced over all color changes in acetylated wood coated with nano $\mathrm{ZnO}$.

Acetylation alone provided significant reduction in total color change $\left(\Delta \mathrm{E}^{*}\right)$ due to UV degradation in comparison with unmodified wood. Though, nano coating on acetylated wood inhibited yellowing of wood, the anticipated synergistic effect of nano material and acetylation was not seen in $\Delta \mathrm{E}^{*}$. The major contribution in $\Delta \mathrm{E}^{*}$ of acetylated wood is from bleaching effect (not color darkening effect). It is important to mention that total color changes $\left(\Delta \mathrm{E}^{*}\right)$ calculated using Equation 2 is not an appropriate parameter to compare the 
UV resistance of chemically modified wood (Nagarajappa and Pandey 2016). This is particularly applicable in the present case as both the color coordinates lightness $\left(\Delta \mathrm{L}^{*}\right)$ and yellowness $\left(\Delta \mathrm{b}^{*}\right)$ follow contrasting behaviour in unmodified and modified wood and the trend is becoming more intense with nanoparticle coating. Therefore, the variation of individual parameters, particularly $\mathrm{L}^{*}$ and $\mathrm{b}^{*}$, rather than $\Delta \mathrm{E}^{*}$, is more important to assess the UV stability as has been reported earlier for certain cases (Tolvaj et al. 2014, Tolvaj et al. 2015, Nagarajappa and Pandey 2016).

\section{FTIR spectra}

Effect of UV irradiation on FTIR spectra of unmodified and modified wood is shown in Figure 5. Rapid lignin degradation in modified wood is evidenced from significant reduction in the absorbance of aromatic skeletal vibration $\left(C=C\right.$ ) peak at $1505 \mathrm{~cm}^{-1}$ and $\mathrm{C}-\mathrm{H}$ deformation vibration peaks at $1456 \mathrm{~cm}^{-1}$ (Pandey 2005, Anderson 1991, Cogulet et al. 2016). Peaks at $1505 \mathrm{~cm}^{-1}$ and $1456 \mathrm{~cm}^{-1}$ almost vanished within $100 \mathrm{~h}$ of irradiation. A corresponding increase in absorption peak due to carbonyl groups at $1730 \mathrm{~cm}^{-1}$ upon exposure indicates photo-oxidation of lignin. As observed in color measurements, bulk of the changes in FTIR spectra were observed during initial period of exposure. Coating of unmodified wood with $\mathrm{ZnO}$ nanodispersion resulted in reduction in lignin degradation and also restricted increase in carbonyl peak upon light irradiation. This indicates effectiveness of nano coating in preventing lignin degradation and explains reduced color changes in coated wood (Nair et al. 2018).
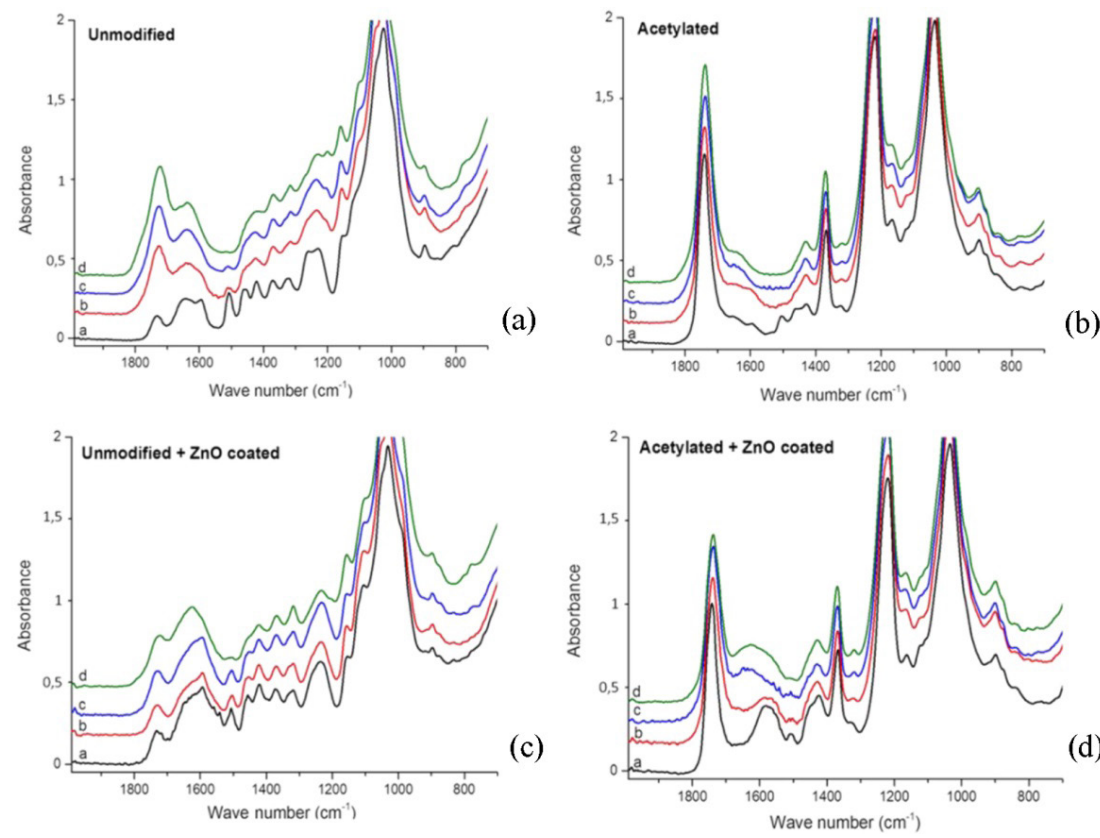

Figure 5: FTIR spectra of unmodified and acetylated wood coated with nano $\mathrm{ZnO}(2 \%)$ exposed to UV for different durations: (a) unexposed, (b) exposed for $50 \mathrm{~h}$, (c) exposed for $100 \mathrm{~h}$, and (d) exposed for $500 \mathrm{~h}$.

FTIR spectra of acetylated wood also indicated lignin degradation as indicated by reduction in bands at $1505 \mathrm{~cm}^{-1}, 1456 \mathrm{~cm}^{-1}$. However, the changes in intensities of other peaks were less pronounced in acetylated wood as compared to unmodified specimens. Further, the carbonyl peak at $1740 \mathrm{~cm}^{-1}$ remained unaffected in acetylated wood indicating effectiveness of acetylation in reducing UV degradation. Color changes in the UV exposed specimens are result of formation of the colored carbonyl compounds released during the photo-degradation. Acetylated wood chemically modifies the hydroxyl groups and makes it less accessible to degradation pathway that is initiated by free radicals. The chemical bonding of acetyl groups with wood constituents interferes with light absorption and hence restricts the degradation from UV light. 
Coating of unmodified wood with $\mathrm{ZnO}$ nanodispersion resulted in reduction in lignin degradation and also restricted increase in carbonyl peak upon light irradiation. This indicates effectiveness of nano coating in preventing lignin degradation and explains reduced color changes in coated wood (Nair et al. 2018). FTIR spectra of acetylated wood coated with nanodispersion also indicate some reduction in lignin degradation. Also, intensity of carbonyl peak remained almost unchanged in acetylated wood coated with nano particles. Nanoparticles are known to protect wood from photo-degradation. Coating of $\mathrm{ZnO}, \mathrm{CeO}_{2}, \mathrm{TiO}_{2}$ nanodispersions protected wood significantly from UV degradation with significant reduction in color changes and FTIR (Nair et al. 2018). The results of this study indicate that effectiveness of nanodispersion coating in unmodified wood is high. Nano coating improved UV resistance of modified wood also. An enhancement in photo-bleaching of wood coated with $\mathrm{ZnO}$ nanoparticle was observed, which increases with increase in $\mathrm{ZnO}$ concentration. $\mathrm{ZnO}$, being a good UV absorber, may undergo some bleaching. The photo-bleaching effect observed in chemically modified wood increased with application of nano-coating.

\section{CONCLUSIONS}

Acetylation slows down the photo-yellowing of wood surfaces. Application of $\mathrm{ZnO}$ nano coating on unmodified and modified wood inhibited photo-discoloration of wood. The apparent higher effectiveness of nanocoating in unmodified wood is due to photo-bleaching effect observed in acetylated wood. The photo-bleaching effect observed in acetylated wood was further enhanced by application of nano $\mathrm{ZnO}$ coating on modified wood surfaces.

\section{ACKNOWLEDGEMENTS}

Financial support from Science and Engineering Research Board (a statutory body of the Department of Science \& Technology), New Delhi (Grant No EMR/2016/004913) is gratefully acknowledged.

\section{REFERENCES}

Afrouzi, Y.M.; Omidvar, A.; Marzbani, P. 2013. Effect of artificial weathering on the wood impregnated with nano-zinc oxide. World Appl Sci J 22(9): 1200-1203. https://doi.org/10.5829/idosi.wasj.2013.22.09.996

Anderson, E.L.; Pawlak, Z.; Owen, N.L.; Feist, W.C. 1991. Infrared studies of wood weathering, part 1: Softwoods. Appl Spectrosc 45(4): 641-647. https://www.osapublishing.org/as/abstract.cfm?URI=as-45-4-641

Bonifazi, G.; Calienno, L.; Capobianco, G.; Monaco, A.L.; Pelosi, C.; Picchio, R.; Serranti, S. 2017. A new approach for the modelling of chestnut wood photo-degradation monitored by different spectroscopic techniques. Environ Sci Pollut Res 24(16): 13874-13884. https://doi.org/10.1007/s11356-016-6047-0

Calienno, L.; Pelosi, C.; Picchio, R.; Agresti, G.; Santamaria, U.; Balletti, F.; Monaco, A.L. 2015. Light-induced colour changes and chemical modification of treated and untreated chestnut wood surface. Stud Conserv 60(2): 131-139. https://doi.org/10.1179/2047058413Y.0000000119

Capobianco, G.; Bracciale, M.P.; Sali, D.; Sbardella, F.; Belloni, P.; Bonifazi, G.; Guidi, M.G. 2017. Chemometrics approach to FT-IR hyperspectral imaging analysis of degradation products in artwork cross-section. Microchem J 132: 69-76. https://doi.org/10.1016/j.microc.2017.01.007

Chang, H.T.; Chang, S.T. 2002. Moisture excluding efficiency and dimensional stability of wood improved by acylation. Bioresour Technol 85(2): 201-204. https://doi.org/10.1016/S0960-8524(02)00085-8

Chang, S.T.; Chang, H.T. 2001. Inhibition of the photodiscolouration of wood by butyrylation. Holzforschung 55(3): 255-259. https://doi.org/10.1515/HF.2001.042 
Clausen, C.A.; Green, F.; Kartal, S.N. 2010. Weatherability and leach resistance of wood impregnated with nano-zinc oxide. Nanoscale Res Lett 5(9): 1464-1467. https://doi.org/10.1007/s11671-010-9662-6

Cogulet, A.; Blanchet, P.; Landry, V. 2016. Wood degradation under UV irradiation: A lignin characterization. J Photochem Photobiol B 158: 184-191. https://doi.org/10.1016/j.jphotobiol.2016.02.030

Cristea, M.V.; Riedl, B.; Blanchet, P. 2010. Enhancing the performance of exterior water- borne coatings for wood by inorganic nanosized UV absorbers. Prog Org Coat 69(4): 432-441. https://doi.org/10.1016/j. porgcoat.2010.08.006

Evans, P.D.; Wallis, A.F.A.; Owen N.L. 2000. Weathering of chemically modified wood surfaces. Natural weathering of Scots pine acetylated to different weight gains. Wood Sci Technol 34: 151-165. https:// doi.org/10.1007/s002260000039

Feist, W.C.; Hon, D.N.S. 1984. Chemistry of weathering and protection. In The Chemistry of Solid Wood. Rowell, R. M. (Ed.) American Chemical Society: Washington DC, USA. Chapter 11: 401-451. https://doi. org/10.1021/ba-1984-0207.ch011

Forsthuber, B.; Schaller, C.; Grull, G. 2013. Evaluation of the photo stabilising efficiency of clear coatings comprising organic UV absorbers and mineral UV screeners on wood surfaces. Wood Sci Technol 47(2): 281-297. https://doi.org/10.1007/s00226-012-0487-6

Giridhar, B.N.; Pandey, K.K.; Prasad, B.E.; Bisht, S.S.; Vagdevi, H.M. 2017. Dimensional stabilization of wood by chemical modification using isopropenyl acetate. Maderas-Cienc Tecnol 19(1): 15-20. http:// dx.doi.org/10.4067/S0718-221X2017005000002

Gonzalez de Cademartori, P.H.; Missio, A.L.; Dufau Mattos, B.; Gatto, D.A. 2015. Natural weathering performance of three fast-growing Eucalypt woods. Maderas-Cienc Tecnol 17(4): 799-808. http://dx.doi. org/10.4067/S0718-221X2015005000069

Habibzade, S.; Omidvar, A.; Farahani, M.R.M.; Mashkour, M. 2014. Effect of nano-ZnO on decay resistance and artificial weathering of wood polymer composite. J Nanomater Mol Nanotechnol 3:3. http:// dx.doi.org/10.4172/2324-8777.1000146

Hon, D.N.S. 2001. Weathering and Photochemistry of wood. In Wood and Cellulosic Chemistry. Hon, D.N.S.; Shirashi, N. (Eds.), Marcel Decker Ink.: New York., USA. p. 525-555.

Hon, D.N.S.; Chang, S.T. 1984. Surface degradation of wood by ultraviolet light. J Polym Sci A 22(9): 2227-2241. https://doi.org/10.1002/pol.1984.170220923

Jebrane, M.; Sebe, G.; Cullis, I.; Evans, P.D. 2009. Photostabilization of wood using aromatic vinyl esters. Polym Degrad Stab 94(2): 151-157. https://doi.org/10.1016/j.polymdegradstab.2008.11.013

Kalnins, M.A. 1984. Photochemical degradation of acetylated, methylated, phenylhydrazine modified and ACC-treated wood. J Appl Polym Sci 29(1): 105-115. https://doi.org/10.1002/app.1984.070290111

Lowry, M.S.; Hubble, D.R.; Wressell, A.L.; Vratsanos, M.S.; Pepe, F.R.; Hegedus, C.R. 2008. Assessment of UV-permeability in nano-ZnO filled coatings via high throughput experimentation. $J$ Coat Technol Res 5(2): 233-239. https://doi.org/10.1007/s11998-007-9064-6

Matsuda, H. 1996. Chemical modification of solid wood. In Chemical Modification of lignocellulosic materials. Hon, D.N.S. (Ed.). Marcel Dekker: New York, USA. p. 159-183.

Mitsui, K. 2010. Acetylation of wood causes photobleaching. J Photochem Photobiol B 101(3): 210-214. https://doi.org/10.1016/j.jphotobiol.2010.07.005

Muller, U.; Ratzsch, M.; Schwanninger, M.; Steiner, M.; Zobi, H. 2003. Yellowing and IR changes of spruce wood as a result of UV-irradiation. J Photochem Photobiol B 69(2): 97-105. https://doi.org/10.1016/ S1011-1344(02)00412-8. 
Nagarajappa, G.B.; Pandey, K.K. 2016. UV resistance and dimensional stability of wood modified with isopropenyl acetate. J Photochem Photobiol B 155: 20-27. https://doi.org/10.1016/j.jphotobiol.2015.12.012

Nagarajappa, G.B.; Pandey, K.K.; Shinde, A.; Vagdevi, H.M. 2015. N-Bromosuccinimide (NBS)-An efficient catalyst for acetylation of wood. Holzforschung 70(5): 421-427. https://doi.org/10.1515/hf-2015-0088

Nair, S.; Nagarajappa, G.B.; Pandey, K.K. 2018. UV stabilization of wood by nano metal oxides dispersed in propylene glycol. J Photochem Photobiol B 183: 1-10. https://doi.org/10.1016/j.jphotobiol.2018.04.007

Oberhofnerová, E.; Pánek, M.; García-Cimarras, A. 2017. The effect of natural weathering on untreated wood surface. Maderas-Cienc Tecnol 19(2): 173-184. http://dx.doi.org/10.4067/S0718-221X2017005000015

Ohkoshi, M. 2002. FTIR-PAS study of light induced study in the surface of acetylated or poly ethylene glycol-impregnated wood. J Wood Sci 48(5): 394-401. https://doi.org/10.1007/BF00770699

Pandey, K.K. 2005. Study of effect of photo-irradiation on surface chemistry of wood. Polym Degrad Stab 90(1): 9-20. https://doi.org/10.1016/j.polymdegradstab.2005.02.009

Pandey, K.K.; Chandrashekar, N. 2006. Photostability of wood surfaces esterified by benzoyl chloride. J Appl Polym Sci 99(5): 2367-2374. https://doi.org/10.1002/app.22685

Pandey, K.K.; Pitman, A. 2002. Weathering characteristics of modified rubberwood (Hevea brasiliensis). J Appl Polym Sci 85(3): 622-631. https://doi.org/10.1002/app.10667

Pandey, K.K.; Srinivas, K. 2015. Performance of polyurethane coatings on acetylated and benzoylated rubberwood. Eur J Wood Wood Prod 73(1): 111-120. https://doi.org/10.1007/s00107-014-0860-2

Pandey, K.K.; Vuorinen, T. 2008. Comparative study of photodegradation of wood by a UV laser and a xenon light source. Polym Degrad Stab 93(12): 2138-2146. https://doi.org/10.1016/j.polymdegradstab.2008.08.013

Plakette, D.V.; Dunningham, E.A.; Singh, A.P. 1996. Weathering of chemically modified wood. In Chemical Modification of lignocellulosic materials, Hon, D.N.S. (Ed). Marcel Dekker: New York, USA. p. 277-294.

Rowell, R.M. 2005. Chemical modification of wood. In Handboook of Wood Chemistry and Wood Composite. Rowell, R.M. (Ed). Taylor and Francis, CRC Press: Florida, USA. p. 381-420.

Rowell, R.M. 2006. Chemical modification of wood: a short review. Wood Mat Sci Eng 1(1): 29-33. https://doi.org/10.1080/17480270600670923

Rowell, R.M. 2013. Chemical modification of wood. In Handboook of Wood Chemistry and Wood Composite. Rowell, R.M. (Ed). Taylor and Francis CRC Press: Florida, USA. p. 537-598.

Rowell, R.M. 2017. Mechanism of exterior coating performance of acetylated wood. In Lignocellulosic Fibre and Biomass-Based Composite Materials. Processing properties and applications. Jawaid, M.; Tahir, P.M.; Saba, N. (Ed). Woodhead publishing: USA. p. 409-422.

Sahin, H.T.; Mantanis, G.I. 2011. Colour changes in wood surfaces modified by a nanoparticulate based treatment. Wood Res-Slovakia 56(4): 525-532. http://www.woodresearch.sk/wr/201104/08.pdf

Salla, J.; Pandey, K.K.; Srinivas, K. 2012. Improvement of UV resistance of wood surfaces by using zinc oxide nanoparticles. Polym Degrad Stab 97(4): 592-596. https://doi.org/10.1016/j.polymdegradstab.2012.01.013

Takahashi, M. 1996. Biological properties of chemically modified wood. In Chemical Modification of lignocellulosic materials. Hon, D.N.S. (Ed). Marcel Dekker: New York, USA. p. 331-361.

Temiz, A. Terziev, N.; Jacobsen, B.; Eikenes, M. 2006. Weathering, water absorption, and durability of silicon, acetylated, and heat-treated wood. J Appl Polym Sci 102(5): 4506-4513. https://doi.org/10.1002/ app. 24878 
Timar, M.C.; Varodi, A.M.; Gurau, L. 2016. Comparative study of photodegradation of six wood species after short-time UV exposure. Wood Sci Technol 50(1): 135-163. https://doi.org/10.1007/s00226-015-0771-3

Tolvaj, L.; Faix, O. 1995. Artificial ageing of wood monitored by DRIFT spectroscopy and CIEL*a*b* colour measurements. 1. Effect of UV light. Holzforschung 49(5): 397-404. https://doi.org/10.1515/ hfsg.1995.49.5.397

Tolvaj, L.; Nemeth, R.; Pasztory, Z.; Bejo, L.; Takats, P. 2014. Colour stability of thermally modified wood during short-term photodegradation. BioResources 9(4): 6644-6651. https://ojs.cnr.ncsu.edu/index.php/ BioRes/article/view/6080

Tolvaj, L.; Popescu, C.B.; Molnar, Z.; Preklet, E. 2015. Effects of air relative humidity and temperature on photodegradation processes in beech and spruce wood. BioResources 11(1): 296-305. https://ojs.cnr.ncsu. edu/index.php/BioRes/article/view/BioRes_11_1_296_Tolvaj_Air_Relative_Humidity_Photodegradation

Vollmer, S.; Evans, P.D. 2013. Performance of clear coatings on modified wood exposed to the weather for 2 years in Australia. Int Wood Prod J 4(3): 177-182. https://doi.org/10.1179/2042645313Y.0000000042

Williams, R.S. 2005. Weathering of wood In Handbook of Wood Chemistry and Wood Composites. Rowell, R.M. (Ed). Taylor and Francis, CRC Press: Florida, USA. p. 139-185.

Zivkovic, V.; Arnold, M.; Pandey, K.K.; Richter, K.; Turkulin, H. 2016. Spectral sensitivity in the photodegradation of fir wood (Abies alba Mill.) surfaces: correspondence of physical and chemical changes in natural weathering. Wood Sci Technol 50(5): 989-1002. https://doi.org/10.1007/s00226-016-0834-0 